\section{Trends in the Alaskan Bottom- Trawl Fishery from 1993 to 2015: A GIS-based Spatiotemporal Analysis}

\author{
Carrie Steves \\ University of Southern California, Los Angeles, USA
}

Gl_Forum 2019, Issue 1

Page: 87 - 104

Full Paper

Corresponding Author:

carriesteves@gmail.com

DOI: 10.1553/giscience2019_01_s87

\begin{abstract}
Using fishery-dependent observer data from National Marine Fisheries (NMFS) provides insight into the location and intensity of bottom-trawl fishing effort, and allows those areas most exposed to fishing pressure to be identified. In this study, the spatial and temporal extent of Alaskan bottom-trawl fishing effort in the Bering Sea, Aleutian Islands and Gulf of Alaska between 1993 and 2015 is explored within a space-time cube in ArcGIS Pro. The variables analysed were number of hauls per area and total catch per area. Statistical techniques were used to examine spatiotemporal clustering within the data. Results indicate that fishing was significantly clustered over space and time. A three-dimensional hotspot analysis shows which areas were most intensely fished and illustrates the trends over the relatively long study period. The data were then compared with sea ice concentration to determine the effect of changing climate on fishing activity. Sea ice had a limited effect on the spatial patterns of fishing effort, but certain areas in the Bering Sea exhibited increased fishing effort in years with less sea ice.
\end{abstract}

\title{
Keywords:
}

spatiotemporal analysis, marine fisheries, hotspot analysis

\section{Introduction}

The use of bottom-trawl fishing gear in the Bering Sea, Aleutian Islands and Gulf of Alaska is a sustainability concern because heavy ropes and nets impact the benthic layer directly. The direct environmental impact of bottom-trawling increases proportionally with increased fishing effort and intensity (National Research Council Staff 2002). (For the definition of 'effort' as used in this article, see section 3.1 below.) In this study, the spatial analysis of commercial bottom-trawl fishing effort shows the locations with the most intense fishing pressure. This analysis also shows how the fishery has evolved over time in response to changes in the environment. Globally, sustainable fishing is at the forefront of providing food for an ever-growing population while ensuring that fish stocks are available for future generations. The goal is to protect not only the food resources, but also the ecosystems that support them (Bellido et al., 2011). 


\subsection{Related Work}

This study draws on past research to produce a successful methodology for analysing trends in the Alaskan bottom-trawl fishery. Many of these past studies see the spatial "footprint" of fishing effort as a direct indication of the location and intensity of environmental impact (Russo et al., 2016; Port et al., 2016; Stewart et al., 2010; Kaiser et al., 2016), describing the need to focus on the changes in fishing patterns in both space and time. We address this challenge by analysing the situation using the space-time cube in ArcGIS Pro.

The hotspot analyses were chosen based on the work by Jalali et al. (2015), Lewison et al. (2009), Bjorkland et al. (2015), Stewart et al. (2010), and Maina et al. (2016). The method is particularly successful in identifying the areas that were most intensely used by the bottomtrawl fishing fleet in Alaska. Past studies provide evidence that hotspots exist in fisheries both globally and regionally, and are important for understanding locations most impacted by fishing activity.

Additional studies provide insight into the spatial history of commercial fishing, which can be essential in recognizing the spatiotemporal patterns of overfishing, impact, and the growth, expansion and evolution of fishing activity. Port et al. (2016) used historical datasets to identify the key economic areas used most consistently and areas where the fleet had expanded into newer territory. Miller et al. (2014) also discovered long-term trends of expansion, showing that fishing vessels travel farther, fish deeper, and fish in more inclement weather. Overall, catch and vessel productivity have not decreased over time. It is evident that obtaining fish is becoming more difficult in historically productive areas, and that new areas farther from shore are being used to supplement the traditional fishing grounds.

The Bering Sea is subject to seasonal ice coverage, which normally forms in December or January, with the peak extent usually occurring in February or March. The presence of seasonal sea ice is a driving factor of the ecosystem as a whole. Climate change models predict that the temperature in the Bering Sea region will increase by 1 or 2 degrees Celsius by 2040. In this same time period, the amount of sea ice is expected to remain highly variable, but the probability of warm years with less sea ice occurring increases over time (Hermann et al., 2015).

Decreasing sea ice cover in the Bering Sea could have a major impact on the commercial fishing fleet. The effect of varying sea ice conditions in 1999-2009 in the Eastern Bering Sea region on Catch Per Unit Effort (CPUE) values was assessed by Pfeiffer and Haynie (2012). Sea ice concentration data was used to characterize the availability of fishing grounds during the winter season. The study indicated some reorganization of fishing effort from warm years to cold years, but overall they found that for all years most fishing effort did not occur in ice-affected areas.

The work by Pfeiffer and Haynie (2012) inspired much of the methodology used here to describe ice cover for the bottom-trawling fishery in the Bering Sea. A historical view of variable ice effects on the spatial distribution of bottom-trawl fishing effort shows how the 
fleet may react to increased availability of fishing grounds during the winter season. With sea ice extent and duration expected to decline due to global climate change, significant shifts in fishing intensity and location may result. The bottom-trawl fishing fleet's response to past sea ice anomalies may help in predicting the future impact of climate change in the Bering Sea.

\section{Objectives}

Three main research questions were explored using a space-time cube:

1. Does Alaskan bottom-trawl fishing effort occur in non-random clusters?

2. Has the intensity or spatial extent of Alaskan bottom-trawl fishing effort expanded from 1993 to 2015?

3. How did seasonal sea ice affect the spatial pattern of Alaskan bottom-trawl fishing effort between 1993 and 2015?

Clustering is examined using Moran's I to measure spatial autocorrelation. The intensity and spatial extent of fishing activity are shown in a space-time cube with two-dimensional and three-dimensional hotspots. These results are compared with sea ice data to visualize the effect of reduced sea ice.

\section{Data Description}

\subsection{Fishing Effort}

Effort is represented in this study by two metrics: (1) total catch per area represents the magnitude of the removal of resources; (2) number of hauls per area by fishing vessels. Both metrics are representative of fishing intensity and are used to describe how this fishery has changed throughout the study period.

The data used in the spatial analysis was collected by at-sea NMFS observers. The observers collected haul-level catch and effort information, including exact spatial locations, duration and independent estimates of catch. The observer data collection covers a large range of vessels and target fisheries, providing an in-depth look at fishing activity in Alaska. Only those vessels carrying observers are included. This fishery-dependent dataset should not be considered a representation of exact totals, but it does give a general description, acceptable for the purposes of this study, of when and where bottom-trawl fishing occurred (AFSC 2016). The limitations of the available fishery-dependent dataset reduced spatial resolution and leaves the possibility of missing or omitted data points. Despite these shortfalls, it is the best publicly available dataset to represent fishing activity in this area. 


\subsection{Sea Ice}

Sea ice concentration data is available through the National Snow and Ice Data Center (NSIDC) and is collected via the Nimbus-7 SMMR and DMSP SSM/I-SSMIS Passive Microwave satellite instruments (Cavalieri et al., 1996). Images have a $25-\mathrm{km}$ resolution and depict daily sea ice concentration, based on brightness and temperature, for the entire polar region. This study required daily files for the full extent of the study site from 1993 to 2015, which were then processed into a total annual sea ice effect index. The index represents the number of days per year of sea ice coverage. Sea ice effect was limited to $20 \%$ ice concentration or greater. The presence of ice is not representative of a no-entry line for fishing vessels; it should be considered simply as a guideline that shows areas which vessels are less likely to enter.

\section{Methodology and Results}

\subsection{Spatial Autocorrelation}

The effort dataset was first tested for the existence of non-random clustering of effort levels. The Global Moran's I tool gives a measure of spatial autocorrelation, showing that the spatial patterns of fishing effort distribution are not created by random events but demonstrate distinct clustering or dispersion. The results were used to find the peak level of spatial autocorrelation. This peak level was used as the distance band threshold for the spatial neighbourhood of the hotspot analysis.

The results of the Global Moran's I statistic indicate strong clustering, with a positive index result for all years, tested separately, for total annual catch and total annual number of hauls. Incremental spatial autocorrelation tested the Global Moran's I statistic for distance bands with $5-\mathrm{km}$ increments and determined the scale at which the most intense spatial clustering is found. The increment values with the peak $z$-score for each year of data are shown in Figures 1 and 2. Peak z-score distance bands range from $45 \mathrm{~km}$ to $105 \mathrm{~km}$ in both the total catch and the hauls datasets. This is the ideal range for analysing high and low clusters. 


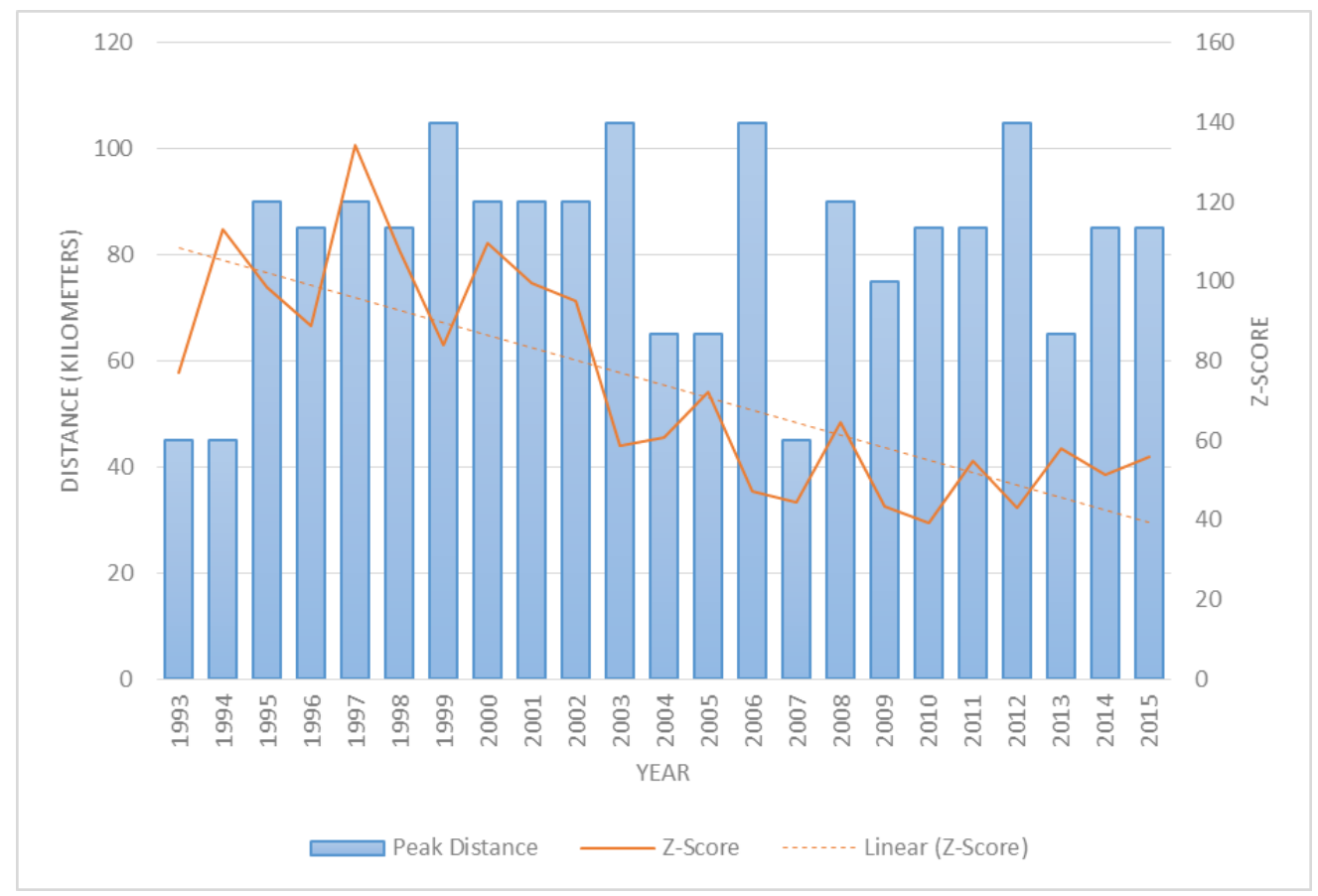

Figure 1: Peak Z-Score Values of Total Annual Catch and Corresponding Distance Band

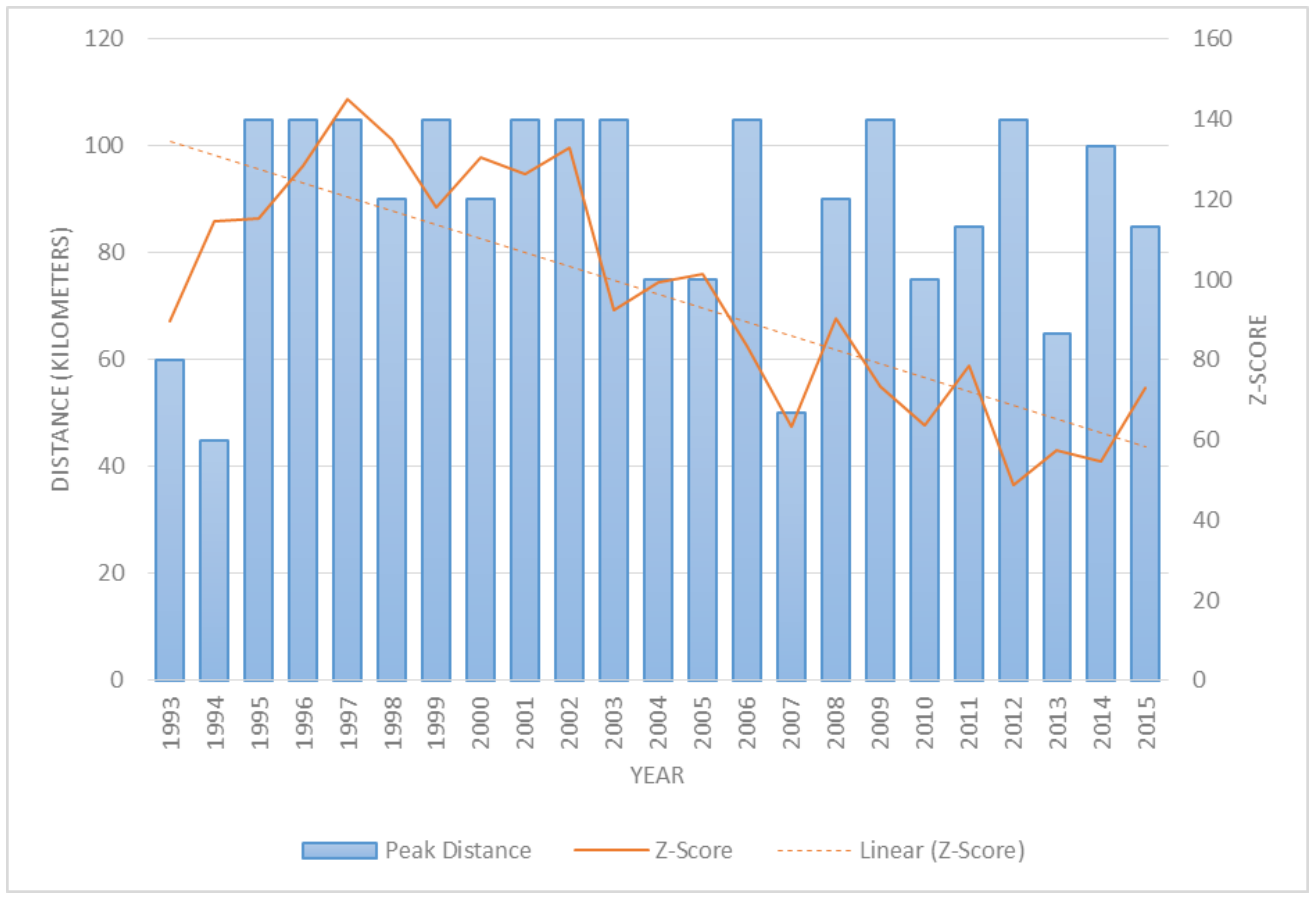

Figure 2: Peak Z-Score Values of Total Annual Number of Hauls and Corresponding Distance Band 
The trend line (dashed) in both charts indicates that the peak z-score decreases over the study period. A decrease in the z-score values between 1993 and 2015 indicates that overall clustering is less pronounced towards the end of the study period in both number of hauls and total catch, although it remains high overall.

\subsection{Space-Time Cube}

Spatiotemporal patterns are difficult to portray using traditional methods, but the space-time cube allows time to be viewed and analysed as a third dimension, with the spatial locations represented by $\mathrm{x}$ and $\mathrm{y}$, and time represented by the $\mathrm{z}$-axis. Each year of fishing data effort is considered as one time slice of the space-time cube. The results of the space-time cube were then further analysed using the Space Time Pattern Mining toolbox, which includes the emerging hotspot analysis tool and 3D visualization tools.

To use the space-time cube tool, all data points must be aggregated into individual spacetime bins. The bins chosen for this study are hexagonal. The hexagon creates more uniform distances between neighbours and is also preferred for higher-latitude study areas because it is less prone to visual distortion. This tool requires the use of a regular grid. The unusual spacing and dimensions of the original (square-celled) aggregation grid could not be used and made it difficult to impose the regular hexagon fishnet onto the data (see Figure 3). This lack of flexibility in the tool at the time of this project was a major limitation to the study results. The hexagon diameter of $30.39 \mathrm{~km}$ was chosen based on area and the results of the incremental spatial autocorrelation tool. Each hexagon is approximately $800 \mathrm{~km}^{2}$, double the area of the $400 \mathrm{~km}^{2}$ grid of the source data. Doubling the area ensured that at least one grid centroid fell within each hexagon. An example area of the resampling process is shown in Figure 3.

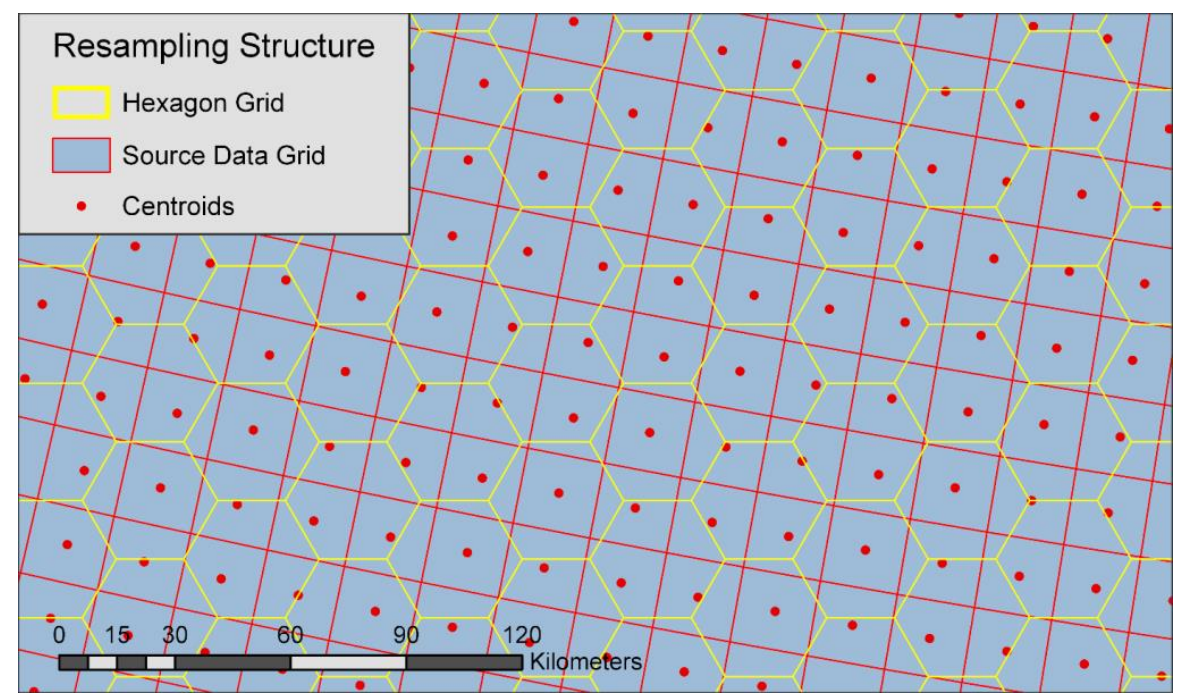

Figure 3: Original Data Format Overlaid with the Hexagon Grid Used in the Space-Time Cube 
The intensity of bottom-trawl effort is represented by assigning the maximum value of all grid centroids that fall within each hexagon bin of the space-time cube. Thus, each hexagon's value is recorded as fishing intensity, but stated in the unit of $400 \mathrm{~km}^{2}$ of the original dataset. By using the maximum, skewing by zeros and cells with no data in edge areas is reduced, while observed magnitudes are retained. The resulting space-time bins contained 0-4 data points from the original NMFS observer data. Bins in active stacks with 0 data points were given an estimated value of 0 . This resulted in the assignment of a 0 value to 11,184 out of a total of 17,595 bins $-64 \%$ of the bins in the space-time cube. Figures 4 and 5 show the two datasets in their three-dimensional forms.

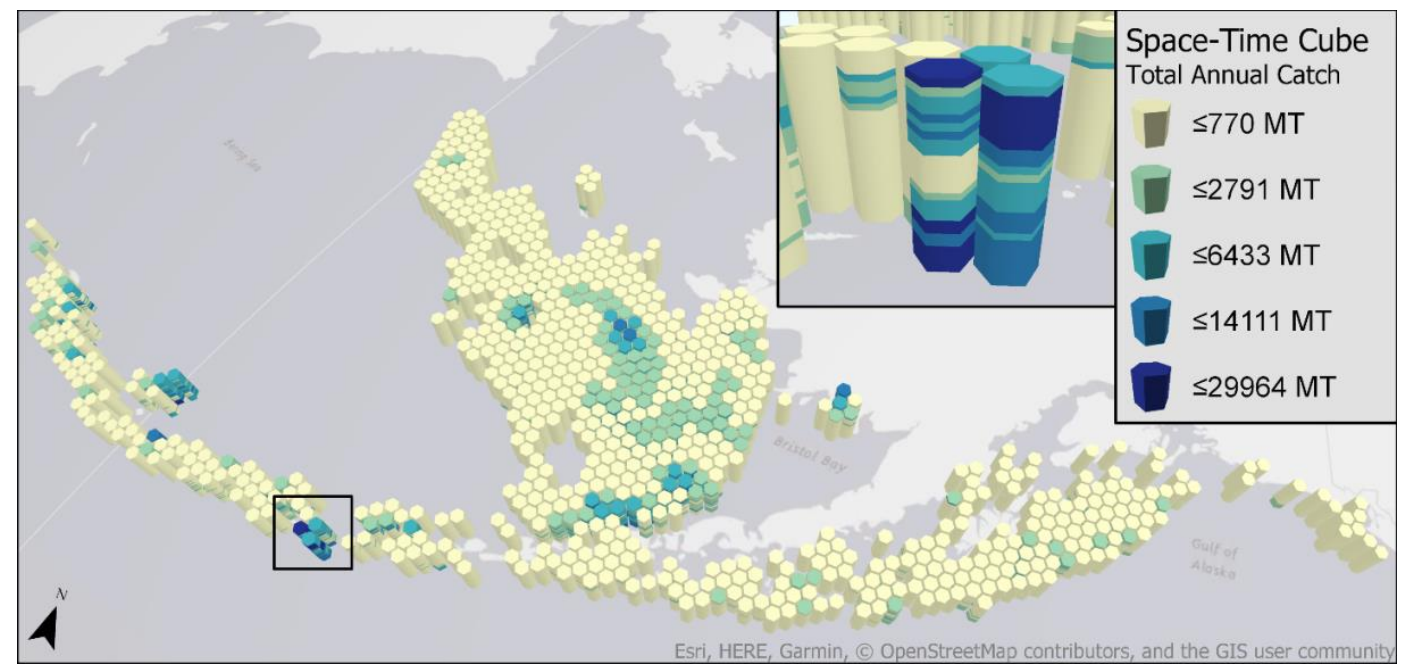

Figure 4: Space-Time Cube Results for Total Annual Catch

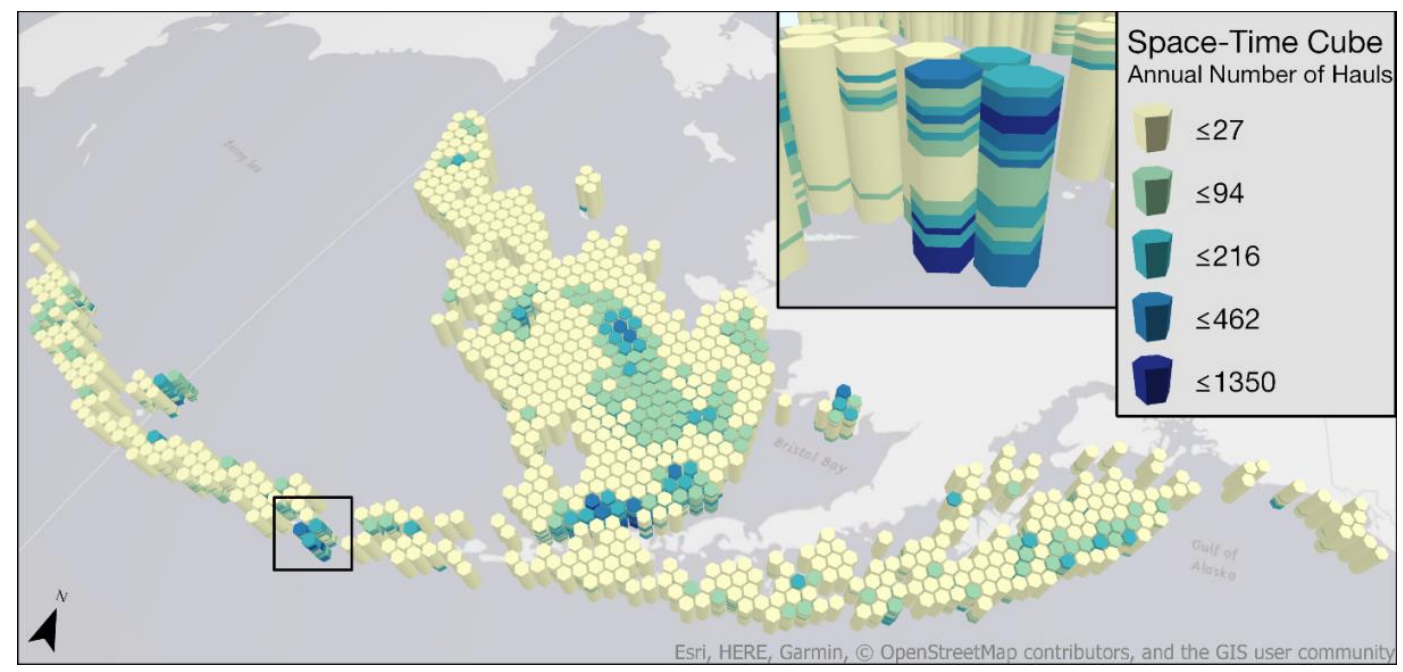

Figure 5: Space-Time Cube Results for Total Annual Number of Hauls 


\subsection{Hotspot Analyses}

The visual identification of spatial patterns is often the first step to discovering and explaining the underlying processes. The space-time cube allows for many different visualizations that uncover different parts of the same story. Bottom-trawl fishing patterns are governed by many complex factors that would be difficult to model or explain with accuracy. Looking at the larger pattern gives insight into a highly diverse fishing fleet and the spatiotemporal patterns of past years.

The emerging hotspot analysis technique improves upon traditional hotspot methods by including time. Rather than running the analysis for each year independently, this technique includes neighbours in both time and space. It was completed using the Getis Ord Gi* statistic, which compares data in each cell with the surrounding cells within the selected space and time parameters.

This method of hotspot analysis, in two dimensions, categorizes each cell based on how often and when the cell has been included in a statistically significant hot- or cold spot (Esri, 2017a). The categories are explained in Table 1. Only one category of cold spots was found in the data; the rest of the cold spot categories have been omitted from the table as none were found in these analyses.

Table 1: Modified Emerging Hotspot Categories (from the ArcGIS Tool Reference)

\begin{tabular}{|l|l|}
\hline Category & Definition \\
Hotspots Intensifying & $\begin{array}{l}\text { Includes new, intensifying and consecutive hotspots. New hotspots } \\
\text { are significant for the final timestep only. Intensifying } \\
\text { hotspots are significant for } 90 \% \text { of the time and have increasing } \\
\text { intensity in the final timesteps. Consecutive hotspots are } \\
\text { significant hotspots for several consecutive timesteps, including } \\
\text { the final timestep. }\end{array}$ \\
\hline Persistent Hotspots & $\begin{array}{l}\text { Persistent hotspots are significant hotspots for 90\% of the } \\
\text { timestep intervals, but have no significant trend of increasing } \\
\text { or decreasing intensity. }\end{array}$ \\
\hline Sporadic Hotspots & $\begin{array}{l}\text { Sporadic hotspots are significant for less than 90\% of the } \\
\text { timestep intervals and at irregular intervals. This category also } \\
\text { includes oscillating hotspots, which may have been cold spots or } \\
\text { hotspots at irregular intervals and were significant for less } \\
\text { than 90\% of the timestep intervals. }\end{array}$ \\
\hline $\begin{array}{l}\text { Diminishing } \\
\text { Historic Hotspots }\end{array}$ & $\begin{array}{l}\text { Diminishing hotspots are significant for 90\% of the timestep } \\
\text { intervals, but have decreasing intensity overall. Historic } \\
\text { hotspots are significant for 90\% of the timestep intervals, but } \\
\text { not significant for the most recent time period. }\end{array}$ \\
\hline Sporadic Cold Spots & $\begin{array}{l}\text { Sporadic cold spots are significant for less than 90\% of the } \\
\text { timestep intervals and occur at irregular intervals. This } \\
\text { category also includes oscillating cold spots, which may have } \\
\text { been hot- or cold spots at irregular intervals and were } \\
\text { significant for less than 90\% of the timestep intervals. }\end{array}$ \\
\hline
\end{tabular}


The hotspot analysis takes into account both consistency and intensity for each timestep to determine a classification of the hot- or cold spot. Time is a more important factor in this analysis than a simple cumulative $z$-score, because each timestep is assessed in relation to the others. The results are shown in Figures 6 and 7.

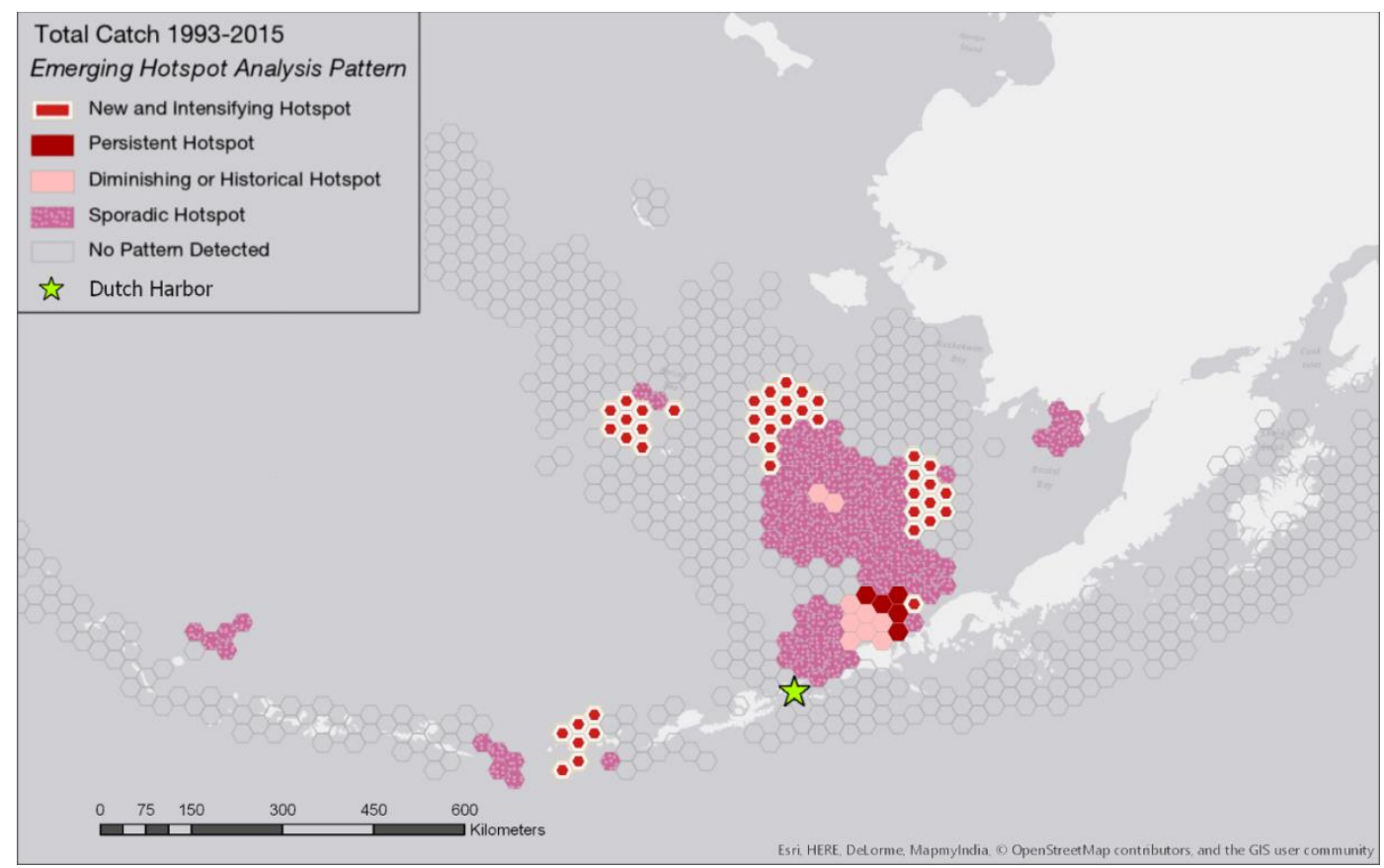

Figure 6: Emerging Hotspot Analysis Results for Total Annual Catch 


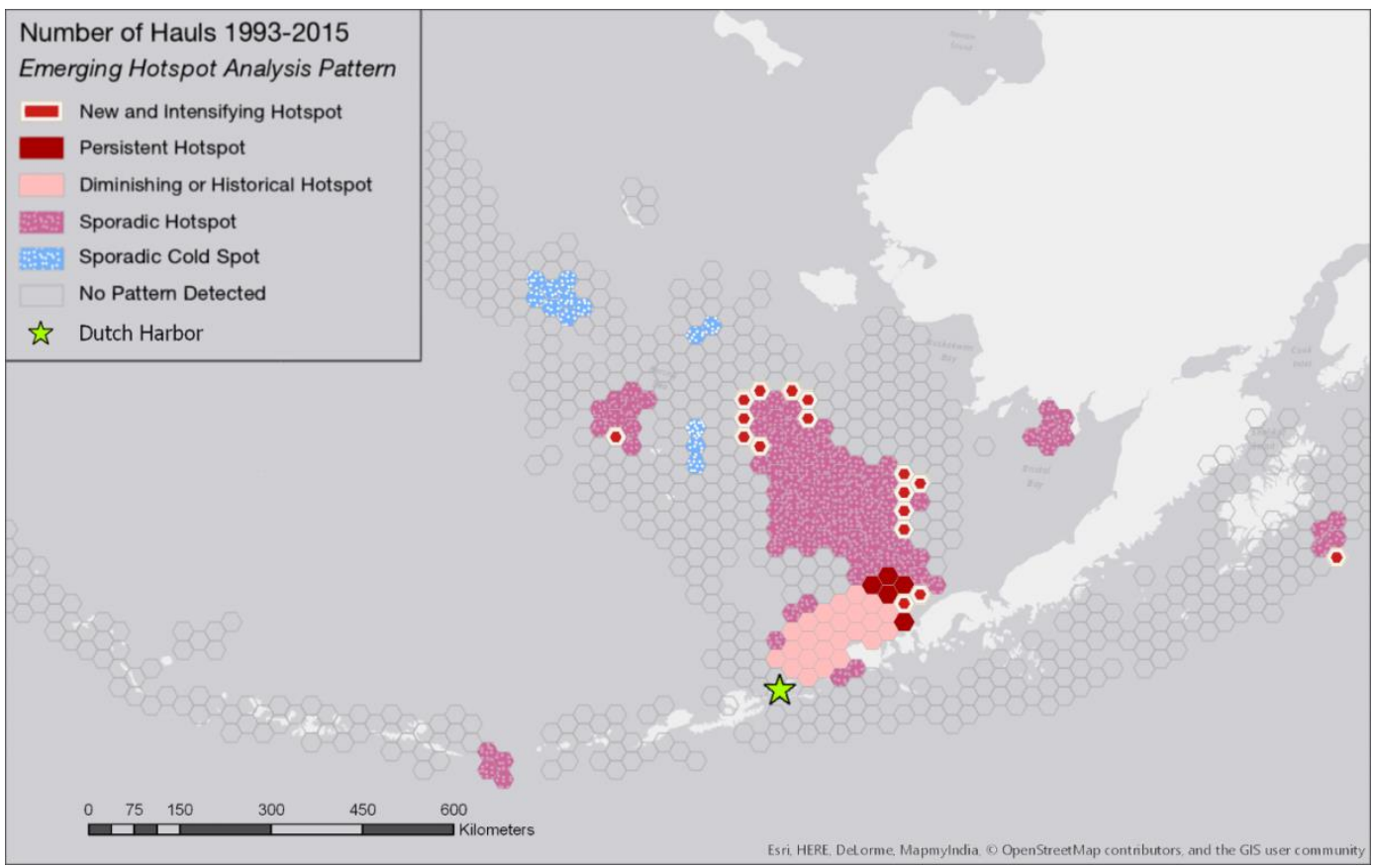

Figure 7: Emerging Hotspot Analysis Results for Total Annual Number of Hauls

Within this region, a clear "core" area is identified as the area most utilized over the study time period. Within this area, there have been sporadic lower values; only a small portion of the core has been persistently used over the 23-year period. The area around Dutch Harbor is classified as a historic or diminishing hotspot. Although this area is consistently identified as a hotspot, its intensity has diminished over time. Areas closest to Dutch Harbor are easier to access for all types of vessel activity and are therefore more prone to be over-utilized. Diminishing catch and fishing effort may signal a depletion of resources.

Both total catch and total number of hauls show that several areas have seen increased usage in the most recent timestep. Many hexagons on the outer edges of the identified hotspot region, particularly the southeastern and northern edges, are classified as new or intensifying. This may indicate expansion into new areas or a shift in resource availability.

Three-dimensional visualizations are particularly useful for displaying the hotspot results. While the hotspot categories identified the areas of interest, a data stack is a more complete visualization of the spatial location's history. The Space Time Cube Explorer add-in for ArcGIS Pro was used to create more detailed views of selected areas and allows the cube to be examined from a variety of viewpoints. Rows can be removed to allow further exploration "inside" the cube, or slices can be removed one by one to dig in from the top down. 
Using this method, areas that were marked new and intensifying in the hotspot analysis can be examined through the entire period. Figures 8 and 9 show an enlarged view of the northern-most area of the identified hotspot region. Most locations became hotspots within the last three timesteps and were only rarely hotspots in the earlier timesteps. This provided evidence that the change in fishing effort has intensified only in the most recent timesteps of the study period.

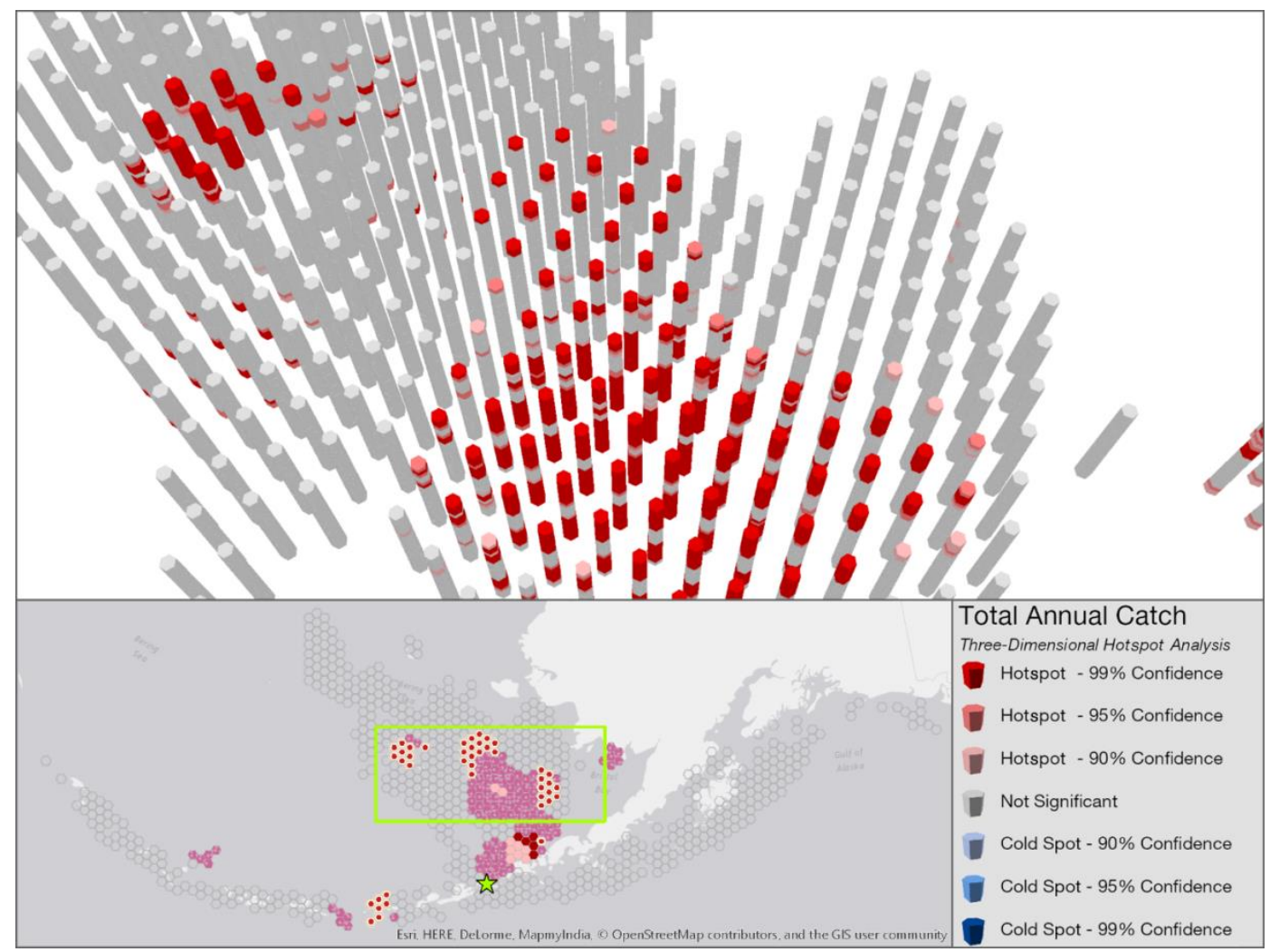

Figure 8: Three-Dimensional Hotspot Analysis Results for Total Annual Catch 


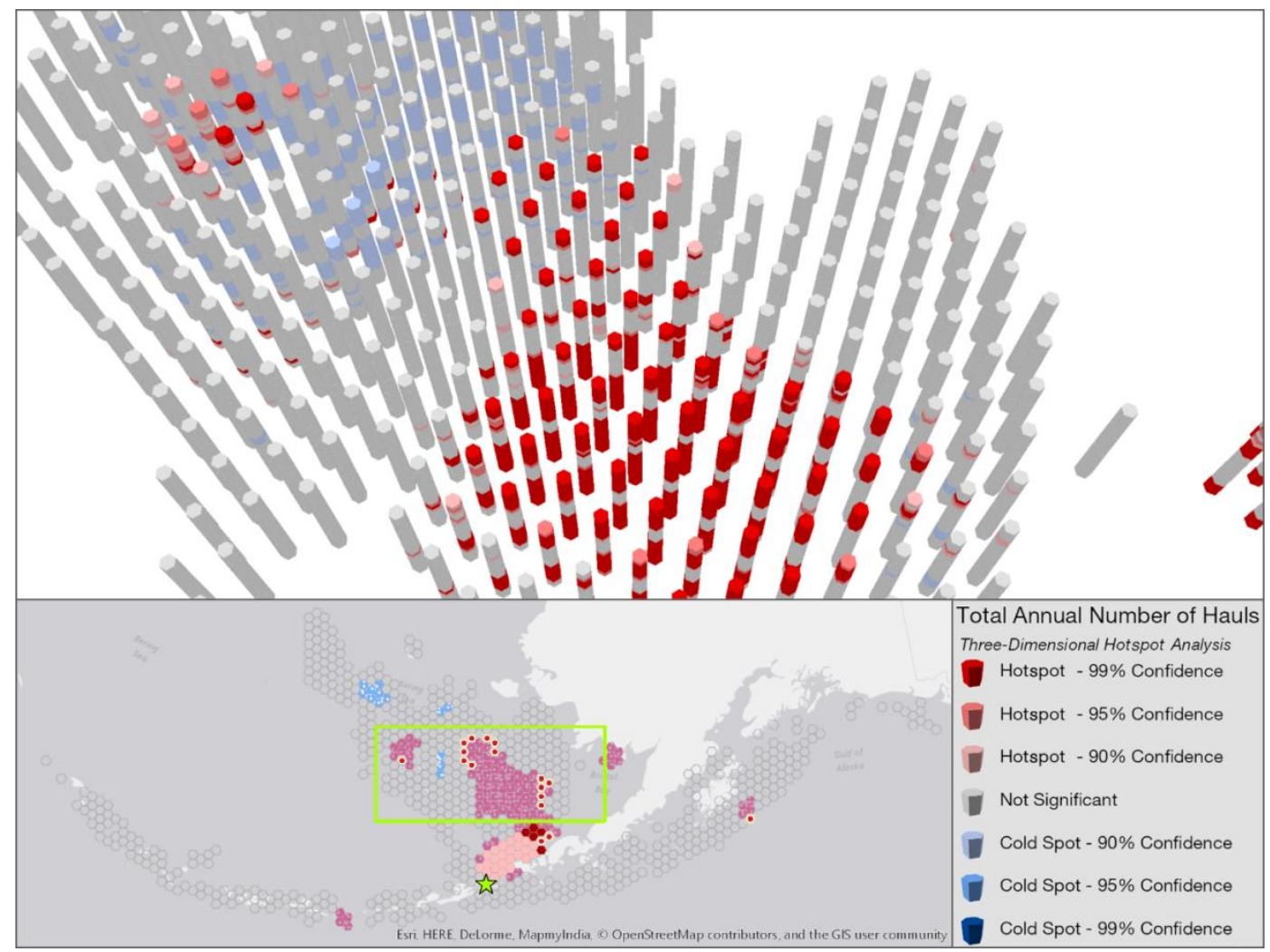

Figure 9: Three-Dimensional Hotspot Analysis Results for Total Annual Number of Hauls

\subsection{Sea Ice Concentration Results}

The Sea Ice Concentration dataset was divided into 'effect areas' (areas affected by the sea ice concentration) according to the number of days per year that they had a $20 \%$ or greater sea ice concentration level. The space-time hexagons were used to match the fishery data for comparison. The average values for the number of days affected by ice for each hexagon is shown in Figure 10. Five levels of ice effect are identified, from No Effect (an average of less than one day per year), to Maximum Effect (150 days per year or more of sea ice). Sea ice affects only the Bering Sea fishing area, with the Aleutian Islands and Gulf of Alaska showing no days affected by sea ice. 


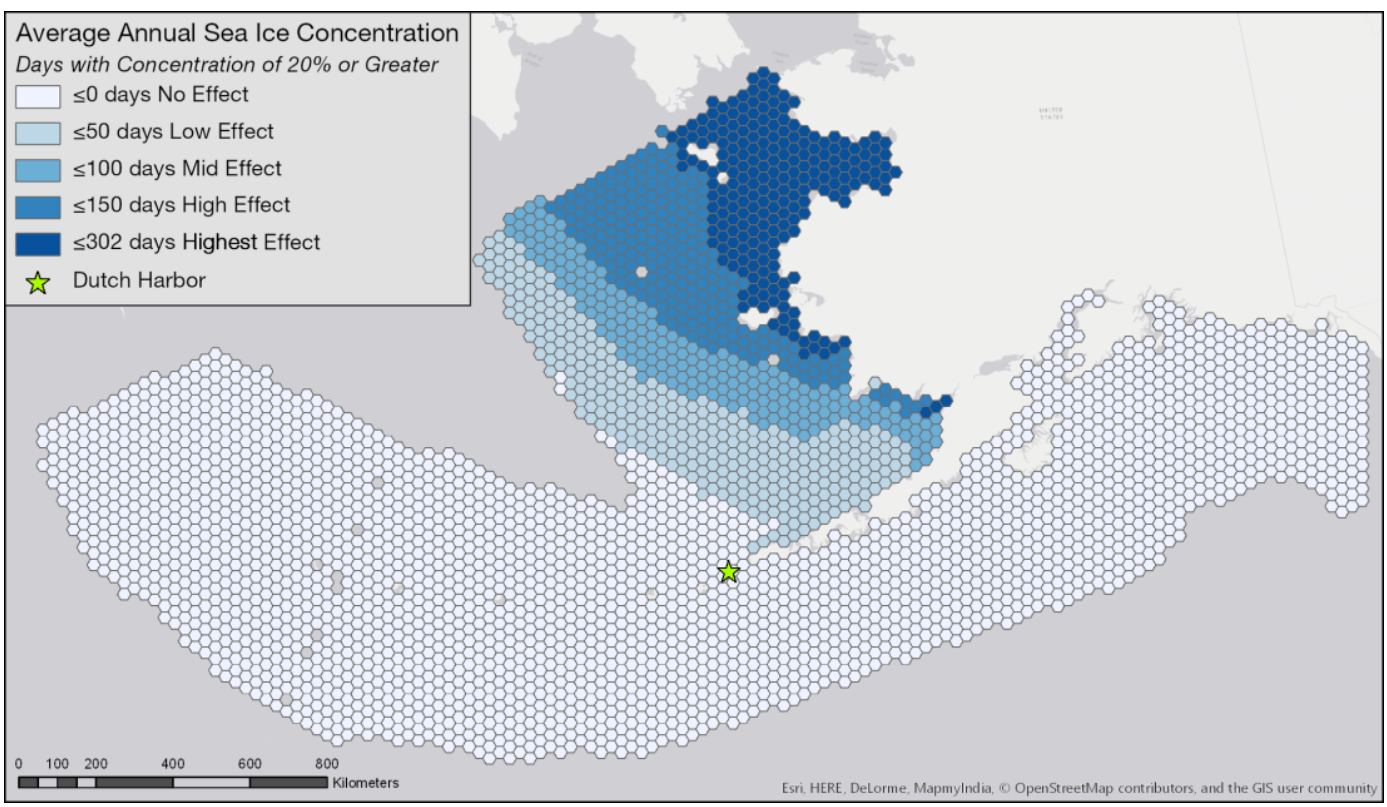

Figure 10: Average Number of Ice Days per Year for each location bin in the space-time cube

To show changes in bottom-trawl activity, fishing effort data were summarized for low iceeffect years and high ice-effect years. The median value of the dataset is 23.14 days per year. The years designated as below-average ice-effect years were 1993, 1996, 2001-2005, and 2014-2015. Average ice-effect years were 1997-1998, 2000, 2006-2007, and 2011. The years designated as above-average ice-effect years were 1994-1995, 1999, 2008-2010, and 20122013. The zones of sea ice effect are shown by the average-effect hexagons in Figure 10. The average catches for each hexagon for the eight years designated as high ice-effect years and for the nine years designated as low ice-effect years are shown in Figure 11. The average annual number of hauls for high ice-effect and low ice-effect years yielded similar results and are not included. 


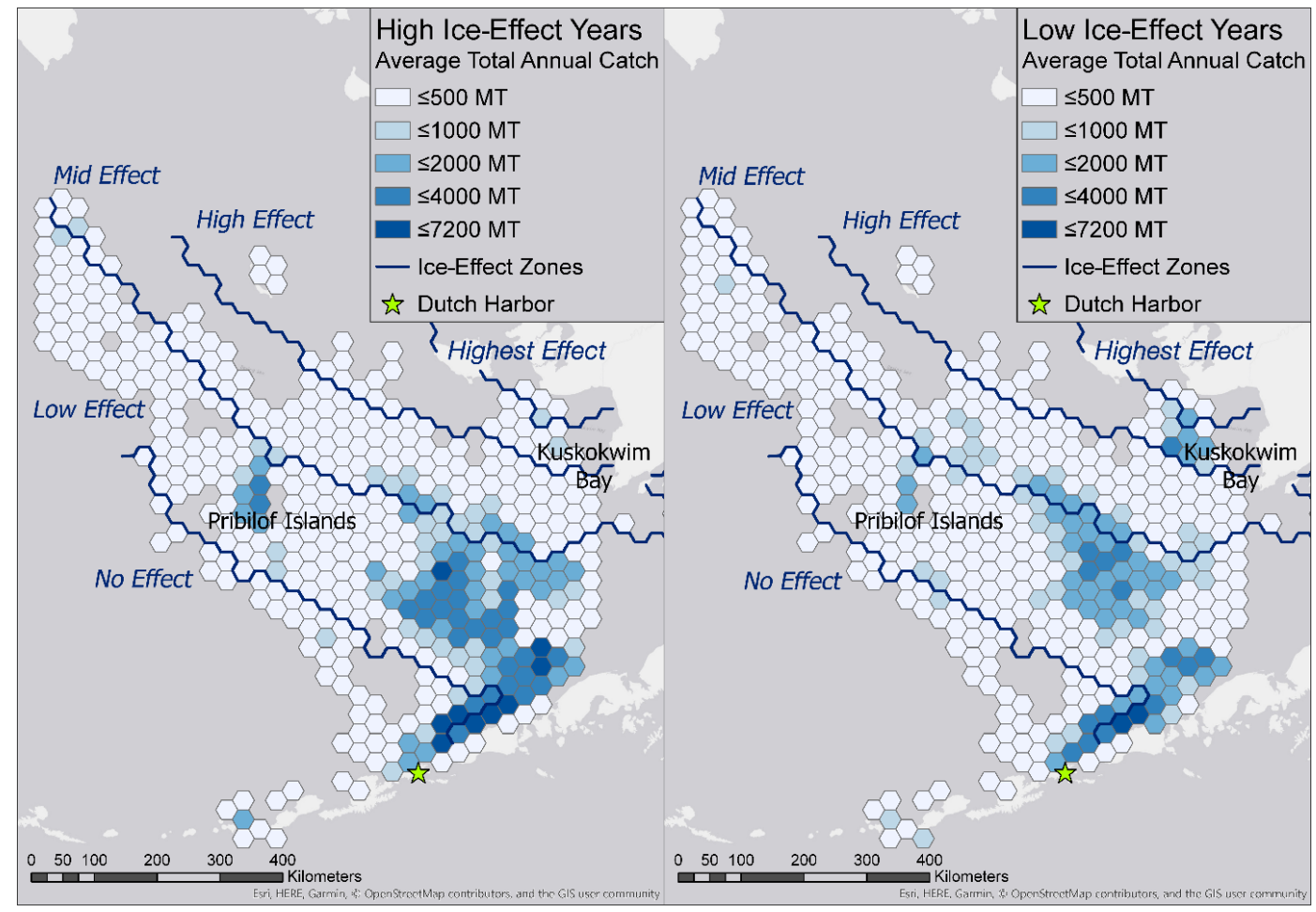

Figure 11: Average Total Annual Catch for High Ice-Effect Years and Low Ice-Effect Years

The presence of sea ice has a noticeable effect on the spatial distribution of fishing effort in all areas of the Bering Sea. Low Ice-Effect years show higher activity in areas designated as mid-effect and high-effect zones of sea ice concentration. This is shown in both datasets, particularly in the areas just outside Kuskokwim Bay and north of the Pribilof Islands. These areas will probably see increased usage as the number of low ice-effect years increases due to global warming. In addition, for both datasets, areas with no sea ice days have decreased average activity during low ice-effect years.

\section{Discussion}

\subsection{Non-Random Clusters}

Fishing effort occurs in non-random clusters and is not homogeneous over space and time. The underlying causes of this clustering are a complex interaction of many factors including, but not limited to, the underlying bathymetry, clustering and schooling behaviour of target species, the fleet's prior knowledge and sharing of information, regulatory parameters, weather conditions and fuel costs. 
Aggregation of the original dataset could reduce the efficacy of this tool if there was increased spatial autocorrelation at a scale smaller than the $400 \mathrm{~km} 2$ grid. Despite this limitation, a range of peak spatial autocorrelations was found between $45 \mathrm{~km}$ and $105 \mathrm{~km}$, after which increased distances reduced spatial autocorrelation. This indicates the need for localized studies of fishing effort rather than summarizing by broader reporting areas. The spatial autocorrelation test also revealed an overall trend of decreasing $z$-score values in the datasets for both the total annual catch and the number of hauls.

\subsection{Expansion of Fishing Areas}

The hotspot analyses identified a common "core" area that encompasses the most utilized area for the bottom-trawl fishing fleet in the Bering Sea. Patterns in the hotspot analyses show that both total annual catch and total number of hauls are increasing in intensity in marginal areas surrounding the core nucleus of fishing activity. This indicates possible expansion into previously less-utilized regions, but not outside the total spatial extent of typical fishing activity. The Gulf of Alaska and the Aleutian Islands did not show a clear nucleus of fishing effort and only sporadic hotspot areas were identified. The expansion of the bottom-trawl fishery in those areas cannot be concluded from this study.

Moving into marginal areas is an environmental concern for several reasons. The move could indicate that resources are no longer as abundantly available in the core area, particularly the area nearest Dutch Harbor, which is more likely to be over-utilized due to its proximity and easy access for all types of fishing vessel (Stewart et al. 2010). Understanding the motivation and underlying causes of fishing effort expansion would greatly improve the resiliency of this fishery.

\subsection{Effect of Seasonal Sea Ice Concentration}

Distinct differences were observed in the spatial distribution of the average number of hauls and catch for high and low ice-effect years. Low ice-effect years show increased annual catch and number of hauls in the area just outside Kuskokwim Bay and the area north of the Pribilof Islands. These areas average 100-150 days of sea ice effect and are likely to see increased usage as the number of low ice-effect years increases due to climate change. The extent to which activity would increase is not apparent from our results.

The study completed by Pfeiffer and Haynie (2012) on the Bering Sea Pollock fishery found changes in effort from warm to cold years, but the overall effect is small, and the fleet is driven more by other factors. Very few hotspots appear in areas that average more than 100 days of sea ice concentration until the final three timesteps, 2013, 2014 and 2015. Both 2014 and 2015 were low ice-effect years, but the pattern does not appear in any other portion of the dataset. This seems to confirm the assertion of Pfeiffer and Haynie (2012) that sea ice concentration has little effect on the spatial distribution of fishing effort. If some vessels moved into new areas, the effort was not sufficient to create a significant hotspot. 


\section{Conclusions}

The aims of this study were to better understand the spatial extent of the bottom-trawl fishery in Alaska and how the extent and intensity of fishing effort have changed over time. Fishing effort is not homogeneous but varies both spatially and temporally due to many underlying factors. Each vessel weighs the various costs and benefits of fishing locations differently, but certain areas are more preferred than others. This leads to increased fishing intensity in predictable spatial locations. The underlying habitat and fish populations in these areas are more exposed to the degradation and loss of diversity caused by repeated fishing pressure (Parnell et al., 2010).

Climate change and its effects can be broad and complex, including changes in water temperature, water currents and species composition. Winter 2015-2016 was the warmest winter for the Arctic in satellite records, and sea ice extent has declined an average of $13.4 \%$ each decade in the Arctic region, which includes the Eastern Bering Sea, since satellite observations began in 1979 (Cullather et al. 2016). This would cause low ice-effect years to increase in frequency and intensity. In general, in areas that are normally affected by ice, the total annual catch and total number of hauls increased during lower ice-effect years.

Organization of the data into the space-time cube was integral to the completion of this project. The cube has proven through this analysis of the bottom-trawl fleet to be a valuable structural format for spatiotemporal trend analysis. Looking at neighbours in both space and time improves the assessment of clusters in the dataset. Each time slice is considered not by itself but as part of the larger time period. Traditionally, this tool has been used for crime statistics, but it could have much wider applications in very different fields. Future research using space-time cube results could be beneficial to many aspects of fishery trends and retrospective spatial analyses. Pairing the results with benthic habitat information would give a more in-depth understanding of the species and habitat types being affected by bottomtrawling. Space-time cube analyses have the potential to better represent fleet behaviour in prediction models, cost/benefit analyses, socio-economic impact analyses, and many other topics of interest for fisheries sciences. Fisheries science would benefit from a much stronger spatiotemporal element in future research.

\section{Acknowledgements}

This research was completed as part of a Master's programme with the help of University of Southern California staff, especially Karen Kemp, Steven Fleming and Travis Longcore. This article is based on the original MSc dissertation (Steves, 2018). 


\section{References}

Alaska Fisheries Science Center (AFSC). (2016). "Data Collected by Groundfish Observers.” Fisheries Monitoring and Analysis Division, North Pacific Observer Program, AFSC, Seattle, WA. Accessed October 15, 2016. http://www.afsc.noaa.gov/FMA/spatial_data.htm

Bellido, J.M., Santos, M.B., Pennino, M.G., Valeiras, X., Pierce, G.J. (2011). Fishery discards and bycatch: solutions for an ecosystem approach to fisheries management? Hydrobiologia 670:317333.

Bellman, M.A., Heppell, S.A., Goldfinger, C. (2005). Evaluation of a US West Coast Groundfish Habitat Conservation Regulation Via Analysis of Spatial and Temporal Patterns of Trawl Fishing Effort. Canadian Journal of Fisheries and Aquatic Sciences 62 (12): 2886-2900.

Bjorkland, R., Dunn, D.C., McClure, M., Jannot, J., Bellman, M.A., Gleason, M., Schiffers, K. (2015). Spatiotemporal patterns of rockfish bycatch in US west coast groundfish fisheries: opportunities for reducing incidental catch of depleted species. Canadian Journal of Fisheries and Aquatic Sciences 72:1835-1846.

Cavalieri D.J., Parkinson, C.L., Gloersen, P., Zwally, H.J. (1996, updated yearly). Sea Ice Concentrations from Nimbus-7 SMMR and DMSP SSM/I-SSMIS Passive Microwave Data, Version 1. Daily. Boulder, Colorado USA. NASA National Snow and Ice Data Center Distributed Active Archive Center. Accessed January 10, 2017.

Cullather, R.I., Lim, Y.K., Boisvert, L.N., Brucker, L., Lee, J.N., Nowicki, S.M.J. (2016). Analysis of the warmest Arctic winter, 2015-2016. Geophysical Research Letters 43.

ESRI. (2017a). "How Emerging Hot Spot Analysis Works." Environmental Research Institute. Accessed April 18, 2017. http://pro.arcgis.com/en/pro-app/tool-reference/space-time-patternmining/learnmoreemerging.htm.

—. (2017b). "How Create Space Time Cube Works." Environmental Research Institute. Accessed April 18, 2017.

http://pro.arcgis.com/en/pro-app/tool-reference/space-time-patternmining/learnmorecreatecube.htm.

Hermann, A.J., Gibson, G.A., Bond, N.A., Curchitser, E.N., Hedstrom, K., Cheng, W., Wang, M., Cokelet, E.D., Stabeno, P.J., Aydin, K. (2015). "Projected future biophysical states of the Bering sea.” Deep Sea Research Part II: Topical Studies in Oceanography 134: 30-47.

Jalali, M.A., Ierodiaconou, D., Gorfine, H., Monk, J., Rattray, A. (2015). Exploring Spatiotemporal Trends in Commercial Fishing Effort of an Abalone Fishing Zone: A GIS-Based Hotspot Model. PLoS ONE 10(5): e0122995.

Kaiser, M.J. et al. (2016). Prioritization of knowledge-needs to achieve best practices for bottomtrawling in relation to seabed habitats. Fish and Fisheries 17:637-663.

Lewison, R.L., Soykan, C.U., and Franklin, J. (2009). Mapping the Bycatch Seascape: Multispecies and Multi-Scale Spatial Patterns of Fisheries Bycatch. Ecological Applications 19(4): 920-930.

Maina, I., Kavadas, S., Katsanevakis, S., Somarakis, S., Tserpes, G., Georgakarakos, S. (2016). A methodological approach to identify fishing grounds: A case study on Greek trawlers. Fisheries Research 183: 326-339.

Miller, R.R., Field, J.C., Santora, J.A., Schroeder, I.D., Huff, D.D., et al. (2014). A Spatially Distinct History of the Development of California Groundfish Fisheries. PLoS ONE 9(6): e99758.

National Research Council Staff, Committee on Ecosystem Effects of Fishing, and National Research Council (U.S.). (2002). Effects of trawling and dredging on seafloor habitat. Washington, D.C: National Academy Press. 
Parnell, P., Dayton, P., Fisher, R., Loarie, C., Darrow, R. (2010). Spatial patterns of fishing effort off San Diego: Implications for zonal management and ecosystem function. Ecological Applications 20(8): 2203-2222.

Pfeiffer, L., and Haynie, A.C. (2012). The effect of decreasing seasonal sea-ice cover on the winter Bering sea pollock fishery. ICES Journal of Marine Science, 69(7): 1148-1159.

Port, D., Perez, J., and Thadeu de Menezes, J. (2016). The evolution of the industrial trawl fishery footprint off southeastern and southern Brazil. Latin American Journal of Aquatic Resources 44(5): 908-925.

Russo, T., D’Andrea, L., Parisi, A., Martinelli, M., Belardinelli, A., Boccoli, F., Cignini, I., Tordoni, M., Cataudella, S. (2016). Assessing the fishing footprint using data integrated from different tracking devices: Issues and opportunities. Ecological Indicators 69: 818-827.

Steves, C. (2018). Trends in the Alaskan Bottom-Trawl Fishery from 1993-2015: A GIS-based Spatiotemporal Analysis. University of Southern California Digital Library.

H ttp://digitallibrary.usc.edu/cdm/ref/collection/p15799coll40/id/389333.

Stewart, K.R., Lewison, R.L., Dunn, D.C., Bjorkland, R.H., Kelez, S., et al. (2010). Characterizing Fishing Effort and Spatial Extent of Coastal Fisheries. PLoS ONE 5(12): e14451 